\title{
Girlhood and Ethics
}

\author{
The Role of Bodily Integrity
}

\section{Mar Cabezas and Gottfried Schweiger}

$\cos$

\begin{abstract}
Our concern is with the ethical issues related to girlhood and bodily integritythe right to be free from physical harm and harassment and to experience freedom and security in relation to the body. We defend agency, positive self-relations, and health as basic elements of bodily integrity and we advocate that this normative concept be used as a conceptual tool for the protection of the rights of girls. We assume the capability approach developed by Martha Nussbaum as an ethical framework that enables us to evaluate girls' well-being and well-becoming in relation to the potential, and often subtle, threats they face. The capability approach can be understood as a theory of justice, and, therefore, as an ethical and political approach. An enriched concept of bodily integrity can help in the design of better policies to address gender biases against girls because it could contribute to seeing them as active agents and valid participants.
\end{abstract}

\section{KEYWORDS}

agency, health, self-relations, vulnerability, well-becoming

\section{Introduction: Framing the Capability Approach and Girls' Rights}

As the original call for articles for this Special Issue of Girlhood Studies on Ethical Practice highlighted, this is a much under-studied area in feminist research, and one which calls for both theoretical frameworks and practical applications. We believe that it is crucial for us to begin with theory so we draw on what economist Amartya Sen (1993, 1997, 2005) refers to as capability theory in an attempt to better capture inequalities and provide a basis for measuring well-being in the lives of girls. The capability approach can be interpreted as a non-ideal normative theory of justice and freedom, and, therefore, as a framework in which to theorize ethical and political challenges concerning girlhood given its bottom-up approach to real problems and its focus on how "social context sets the conditions for individual freedoms" 
(Unterhalter et al. 2007: 13). Nussbaum has further developed the idea of various capabilities as being intimately related to bodily integrity. These capabilities range from being able to lead a life in which health, nutrition, shelter, mobility, reproductive rights and so on feature to being able to play and have fun, and from being able to enjoy education to being able to be free from harmful pain. For Nussbaum, these capabilities should not depend on context but should be universal. In her own words, bodily integrity is a human central capability and consists of "[b]eing able to move freely from place to place, to be secure against violent assault, including sexual assault and domestic violence, having opportunities for sexual satisfaction and for choices in matters of reproduction" (2011: 33). Functionings, in this approach, are not just what human do but what they have already accomplished.

A holistic concept of bodily integrity as applied to girls should make those aspects of control that concern the restrictions imposed on girls and governance over their bodies explicit. There are several reasons for this. First, bodily integrity is itself a multidimensional functioning and capability; it encompasses physical and mental health, positive self-relationships, and agency. In other words, only when a girl is sufficiently healthy, has agency, and a positive relationship with her own body and personhood, can her bodily integrity be satisfied. Second, bodily integrity is not a passive or negative concept based on being protected against various harms, but an active and positive one that necessarily implies that girls are active agents of their own lives, that they need their bodies to function, and that they need to have control over them. Third, girls' bodily integrity is not static; it is dynamic and developing. An adult woman, for example, could have the capability of living a healthy life yet can autonomously decide to follow an unhealthy diet, not as a symptom of an illness like, for instance, anorexia, but simply as a free decision on how to lead her own life. Girls' bodily development, however, needs a balance between protection and personal agency. Here, the notion of agency refers to certain cognitive, emotional, and psychological features the agent may possess, and her ability to influence her environment and the persons in it. Our emphasis on the need for special protection for girls does not mean to render their agency invisible. On the contrary, the aim of this protection is to guarantee their agency through the capability of their bodily integrity.

Despite the requirements of the UN Convention of the Rights of the Child (CRC) (UN 1989) alongside the Beijing Convention on Women Rights (UN 1995) there still remains a gap in the awareness of subtle and specific threats and challenges that affect girls because of the concurrence of two (potential or actual) biases — those related to gender and those related 
to childhood. Nura Taefi (2009) has called this the intersectionality of age and gender in that females are protected in a fragmentary way either as children or as women with its subsequent fragmentation of their identity. The $\mathrm{UN}$ initiative that focused on education for girls ${ }^{1}$ is a valuable step towards the materialization of girls' rights through concrete measures. However, a holistic approach that includes the perspectives of girls is still missing. Such an approach might better coordinate efforts and avoid re-victimizations and potential inconsistencies among different areas of feminist work, namely, those concerning children's rights and those focused on women's rights and gender inequality. The Universal Declaration of Human Rights along with those outlined in CRC have been criticized for their claim of universality ${ }^{2}$ (Ignatieff 2001). Despite their success on paper concerning ratification, many daily ethical issues affecting girlhood remain invisible or untangled from those affecting women.

Bearing the human rights framework in mind, we discuss the capability approach as one philosophical normative approach that could provide a way to help realize the ethical demands of justice for girls. We focus on the capability and functioning of bodily integrity, which connects physical and mental health, positive self-relationships, and agency. The capability of bodily integrity can help us to visualize how different human areas are interconnected; this is especially relevant for moral damage and vulnerability in relation to girlhood.

Assuming Dixon and Nussbaum's (2012) perspective, we advocate for the connection between their approach to children's rights and the CRC. Nussbaum has also shown that the capability approach is sensitive to gender inequalities and may therefore be an ethical framework that could do justice to marginalized women who are discriminated against. However, Nussbaum (2000, 2003, 2005) has not tackled the specific issue of girls' rights as part of children's rights in the same thorough manner and has overlooked the relevance for girlhood of the distinction between agency and well-being. The capability approach is based on three basic concepts - capabilities, functionings, and conversion factors-that make this approach a suitable tool for building a flexible and open ethical theory.

\section{Capabilities, Functionings, and Conversion Factors}

As we have explained, capabilities are freedoms of a person to do or be something that is of value to him or her. Functionings are the realized capabilities. 
Capabilities describe possibilities while functionings describe actual states of doing or being. Conversion factors refer to the means that are necessary to gain a certain capability, which can then be transformed into a functioning if the person so wishes. For example, a girl has the capability of kicking a soccer ball if she knows how to, is in a physical and mental state to do so, is not prevented by anyone else, has access to a soccer ball and, finally, if the environment allows her to do this. The only obstacle that stands between this person and her kicking a soccer ball—which means achieving this particular functioning - is her own will or preferences. These named conditions are the conversion factors in this case. If one of these is missing, this girl lacks the capability of kicking a soccer ball and hence cannot achieve this functioning. However, whether she thinks she deserves to have access to a soccer ball and whether she thinks she has the resources and strength to reverse any present circumstance preventing her from accessing that experience of kicking it is directly linked to her capabilities related to her self-relationship, which are, in turn, intimately linked to her bodily integrity in terms of agency.

The capability approach demands that human beings be provided with the necessary means and skills to freely live the life they consider worth living; human beings should be able to choose what they want to achieve in their lives. Since the bodily integrity of girls is an underdeveloped notion with great potential for their well-being and well-becoming, we will focus our argument on this capability.

\section{Well-being and Well-becoming of Girls}

Girls' well-being and well-becoming should be ensured by girls' rights. These concepts are obviously multidimensional and complex and rest not only on ethical assumptions about human moral status, vulnerability, dignity, and the need for respect and consideration, but also on empirical knowledge about girls' lives (Bagattini and Macleod 2014). Well-being describes the capabilities and functionings that a girl needs right now as a child to live a good and healthy life. Well-becoming is concerned with what girls need to live a good life as they grow up and become women. Nonetheless, well-being and well-becoming are not merely descriptive concepts; they are normative ones since they include an idea of what one deserves and what would be good for one.

Risk factors for girls' well-being and well-becoming, such as gender inequality, may become threats to girls' functionings. Since these threats are 
likely to endanger girls' bodily integrity and limit their chances to realize their basic freedoms, risk factors can be seen to be an instance of injustice when they are preventing, truncating or putting girls' well-being and wellbecoming at risk. A very simple example is the social double standard used in judging male and female promiscuity that labels girls as sluts and boys as studs. Nearly all aspects that are important for girlhood have some influence on later life, and nearly all aspects of womanhood are to some extent influenced by girlhood (Conroy et al. 2010; Horgan 2009; Landry and Cooper 2014). Well-being and well-becoming should not be understood as merely subjective concepts that reflect only how a girl feels about herself. Rather, they combine objective and subjective elements. There is a need for measurable criteria to objectively estimate a society's level of justice toward girls and to show how an unjust situation, after the application of some social measures, has changed or improved. This would be especially helpful to articulate and eventually avoid ideological biases that could jeopardize girls' freedoms. Therefore, using the theory surrounding the notion of bodily integrity could shed light on where to establish a sufficient threshold since this concept encompasses agency, self-relations, and health. Thus, a society would be more equitable if the basic capabilities of its citizens were granted at least to a threshold where having enough resources for a decent living was secured.

Although we will return to this point later, in relation to the potential conflicts between girls' well-being and caregivers' personal, religious or other cultural positions, the individual is ultimately the subject of rights. To put it differently, the girl, and not a given religion or tradition, is the subject of rights. This is extremely important in the case of girls: her bodily integrity and, in turn, her individual rights can be severely endangered so that a particular cultural and/or religious tradition can continue to exist. Practices such as genital mutilation, forced adolescent marriage, or the behavior expected, under threat of punishment, of adolescent girls in a given society, such as their compliance with what is thought to be appropriate sexual conduct and their role in households are some examples (Aggleton and Parker 2012). Hence, respect for bodily integrity is a useful criterion to employ when respect for cultural traditions threatens to take precedence over respect for the individual girl. Employing such a criterion does not mean falling into moral relativism but, rather, it offers an ethical threshold that should not be surpassed for the sake of respecting cultural differences. In other words, cultural differences should be respected until they threaten to violate the person's bodily integrity, so that the casuistic differences in the lives of girls will not become a perverse argument to justify violations of their rights. 


\section{Girls' Bodily Integrity}

As previously mentioned, we advocate for the notion of the capability of bodily integrity to become a theoretical tool that can be used to elucidate specific vulnerabilities that can go unnoticed with the use of traditional top-down theories of justice. Without dismissing the experiences of boys, we recognize that girls face specific threats such as sexual abuse including coerced prostitution, and interfamily and external violence in radically different ways than do boys (Melrose and Pearce 2013; Upmark et al. 2007). However, clear-cut cases of threats to bodily integrity impressively demonstrate how they harm girls' well-being and well-becoming, influencing their long-term physical and mental health, their agency and, eventually their self-realization (Rafferty 2013; McKenney and Bigler 2016; Shute et al. 2008). For example, girls and women are more likely to be targets of the sexual aggression of men when they are alone at night. Violence against girls and women continues to be permissible in many societies and manifests in the form of rape culture and the policing of the female body. The logic of domination (Warren 1990) is crystalized as part of the cultural context worldwide, which may lead to a double victimization of girls. Here, this refers to being female, belonging to a quantitative or qualitative minority, and being aware of this in that such awareness (and the fear) of having a greater chance of becoming a victim just because of one's sex ${ }^{3}$ presents this second layer of victimization (Finkelhor 1993; DeGue et al. 2012). The sexually abused girl who has also to face cultural and social assumptions about her sexuality and her expression of it, her role in society and in the family (Felix and MacMahon 2006) may end up modulating her own construction of her self in the active exploration and development of "her own conception of what it is she has reason to value" (Unterhalter et al. 2007: 15). The notion of bodily integrity, although valuable for both sexes, becomes especially useful in the case of girlhood, given the active role of the individual in this process and given that girls are still more likely than boys to experience sexism.

If girls' bodily integrity were to be considered a central capability in policy design this would prevent children's rights to physical and mental health, education, housing and so on being seen as unrelated to a child's identity and this would, in turn, make visible many gender-biased violations and threats against girls. In such a scenario instances of gender-related injustice could be better faced and dealt with. It is vital to scrutinize the elements that shape our concept of bodily integrity while providing some examples 
of how this capability could help in visualizing gender biases affecting girls' capabilities and functionings.

We must recognize that sufficiently realized bodily integrity can positively influence other capabilities/functionings. Conversely, when it is violated or truncated, other areas of well-being and well-becoming are heavily affected (Wolff and de-Shalit 2007). Instances of damage related to bodily integrity, which are very common for girls, are corrosive in that they might modulate girls' agency, self-relation, and health. For example, fashion editorials in which women are shown as victims of a collective rape, or as sick, fragile, kidnapped, or objectified might not directly violate any girl's rights, but they may jeopardize and shape girls' self-relation and agency, as well as their physical and psychological health. If the imperative to maintain bodily integrity were to be invoked subtle but long-term corrosive threats to girls' well-being and well-becoming that shape how girls may develop other capabilities/functionings would become apparent. These kind of threats, made apparent, would be seen to be affecting girls' ability to live the kind of life they want to realize. We assume the criterion of sufficiency to establish a demandable threshold regarding social justice. In doing so, we assume that the basic capabilities should be realized and protected at least to a level that could guarantee a decent living for every human being, and we recognize that our understanding of who we want to be is socially co-constructed (Deneulin and McGregor 2010). This recognition is reason enough to reject, ethically, those visions that compromise a minimum development of human capabilities, and especially bodily integrity, while maintaining a certain openness to cultural differences.

When bodily integrity is understood as a combination of several capabilities/functionings, it becomes clear why a right to bodily integrity is of such importance, especially during girlhood, not only insofar as physical and mental health is concerned but also in terms of a positive relationship to the self and to agency. Positive self-relationships are fertile ${ }^{4}$ for the development of the girl, because these positive self-relations are necessary for someone to develop into an independent adult with a strong sense of worthiness (Honneth 2004). Without the achievement of self-confidence, selfrespect, and self-esteem, the development of an undistorted self, capable of making important choices for oneself, is very unlikely. Moreover, these are also fertile for the actual well-being of the girl and the achievement of other capabilities and functions that matter during girlhood. For example, selfconfidence, self-respect and self-esteem are connected to (physical and mental) health, to the ability to participate in social activities, and to engage in 
social relationships, learning, and playing. All these are valuable functions for human beings and may become useful in terms of detecting invisible and subtle violations of girls' rights since these functions shift the focus towards what should be achieved as a matter of justice. Positive self-relationships are not only important; they also influence whether and to what extent other dimensions of a girls' well-being and well-becoming are fulfilled.

Although childhood and femininity are highly socially constructed concepts (Appell 2009; Plumwood 1993), a dialectic balance should be found here between the different social agents interacting with girls so that an appropriate agency develops between the responsibility to protect and the promotion of their evolving capability to act freely. For this reason, it would not be enough to say that women should be "in control of all aspects of their health, in particular their own fertility" (UN 1995), for this prescription can be ambiguous in the case of girls. Rather, we point out the crucial role for girls of a right to bodily integrity, taking into consideration the developing nature of girlhood. This would be a rich way to avoid oppressive paternalistic measures while still protecting girls and thus avoiding the frequent scenarios in which many instances of injustice go unnoticed. In other words, the capability of bodily integrity as a normative guide would avoid despotic measures where the beneficiaries of those measures have no voice. What is known as soft paternalism ${ }^{5}$ seems helpful in reconciling the two ideas of bodily integrity as choice and as protection in the case of girls. Although Nussbaum's capability approach has received some notable criticism for not being sufficiently neutral and for favoring some conceptions of the good life (Claassen 2014), we understand this as a potential advantage of the capability approach compared to formal or deontological ethical theories. The fact that it is not completely neutral avoids the acceptance of moral relativism, so that providing some minimum ethical material standards on what a good life requires could actually benefit the realization of girls' rights.

As a result of some of the limitations of top-down approaches such as principlism, based as it is on the moral principles of autonomy, beneficence, nonmaleficence, and justice, the agency of girls is often misdirected by social and cultural gender-biased assumptions. This aspect, alongside the integration of mental and physical health, agency, and positive self-relationships may be under threat, particularly during adolescence, and in very subtle ways. For example, socially excluded Romani teenage girls in Spain who assume their cultural gender role experience a source of conflict between their expected submission and acceptance of early marriage and the concurrent abandonment of school and their dreams of living what they call a nor- 
mal life (Pitillas and Gómez 2014). The fact that about "one in five women and one in 71 men in the United States have experienced rape or attempted rape in their lifetimes" (DeGue et al. 2012: 1211) is remarkable. According to this research, nearly half of all women and one fifth of all men in this geographical context have experienced other forms of sexual violence. Although this statistic refers to adults, early experiences become a representational template of the world so that indirect victimization during girlhood should not remain unremarked. The development of the ability to discriminate between several threats in a given society is key to how the child will interpret and evaluate a given experience (Garbarino 2000). The same would happen regarding the social expectations of how a girl should behave. As a result, being a girl growing up in a context in which she sees how women are more likely to become victims of a kind of violence (Pinheiro 2006) will modulate whether she sees herself as a potential victim or not, which, in turn, will shape her self-concept and agency by filtering the decisions that she may feel free and comfortable to make. This, alongside other specific cultural and social obstacles and cultural expectations and prejudices about female sexuality makes girls' bodily integrity especially vulnerable (Cook and Dickens 2000).

Since the notion of bodily integrity is based on seeing the person as a whole, it may help to incorporate explicit gender-sensitivity into the capability approach (Robeyns 2003) without assuming that what works for boys works for girls (Greene 2015; Cowie 2012). In the same way, what works for some girls may not work for other girls living in another context or with different needs. Thus, the perspective of the capability approach and the focus on the bodily integrity of girls might be helpful in bringing together the universal moral claims of the discourse of human rights and the need to engage with casuistic differences. This leads to questions regarding the ability to effectively detect and criticize such violations of girls' rights and discern how they can be stopped.

Every right is implemented in a particular social context that is also shaped by views on gender (Croll 2006). While this means that every policy that aims to implement girls' rights will have to deal with such gender roles, the empowerment of girls and the implementation of their rights will not work without changes in many societal contexts. In providing a normative framework for analyzing the living conditions, well-being, and well-becoming of girls, the concept of capability/functioning of bodily integrity is wellsuited to tackle issues concerning the implementation of policies that help overcome injustices concerning girls' rights while also giving space to their 
own agency. Hence, since the emphasis lies on the realization of those capabilities, the capability approach, in being sensitive to the particular threats girls face in today's world (Rafferty 2013; Sauer and Neubauer 2014; Bunting 2005), may turn out to be a suitable approach to help meet their needs. Furthermore, this approach might ensure that girls' rights are not understood in a paternalistic way since girls themselves are entitled to a voice and empowerment according to their capacities, however overlooked an aspect this is in the human rights discourse. As a result, this approach could be ethically valuable in recognizing girls as active agents with moral standing, which, in turn, could facilitate respecting their visions and aims. In other words, the capability approach would make explicit how defending a group's rights without considering that group's voice is already an instance of injustice and indicates a failure to respect it.

\section{The Right to Bodily Integrity in Policy Making}

Defending only a right to health, education or autonomy as compartmentalized areas of a person's life without paying attention to how they are related to each other and to how girls face different challenges and have specific needs, might lead to unfairness. If concrete measures are not implemented, such inequity, in turn, might then be reflected in policy-making. Many voices coming from difference feminisms (Held 1995; Tong et al. 2004) and feminist care ethics (Gilligan 1993), in introducing bottom-up context-specific approaches, and in having pointed out how a universal concept of justice that does not pay attention to contextual differences can become unjust, and therefore perverse, identify significant defects in the top-down justice theories. However, a specific focus on girlhood needs to be established. This could be effected if the capability/functioning of bodily integrity were integrated into girls' rights policies since functionings can be seen as the content of human rights' discourse. Such attention to the design of better policies for girls could help to abolish or at least mitigate gender biases that affect childhood.

As a result of internalized social codes that reinforce passivity in females and aggressiveness in males (Gilligan 1993; Worell and Goodheart 2006), girls' perspectives may be more likely to be invisible in the public sphere. Girls may also be economically dependent even when they are contributing to the household. Being a wage earner, even the main one, is often not associated with being empowered in other social roles (Faizi and Shah 2014) 
and their reduced autonomy and circumscribed social role might still lead to a deep sense of helplessness concerning their own options in their current and future lives. The necessity to work as a child may rob a girl of other opportunities. Besides, as already discussed, girls, and perhaps particularly adolescent ones, suffer a specific gender-biased coercion in terms of social expectations (LeMaire et al. 2016), body image, manners, and habits (Hayes and Tantleff-Dunn 2010), so that opportunities to develop and exercise their bodily agency might also be overlooked.

Although the commitment to "ensure the full implementation of the human rights of women and of the girl child as an inalienable, integral and indivisible part of all human rights and fundamental freedoms" (UN 1995: article 9) is already a milestone in the social and political recognition of girls as subjects of rights, the application of the notion of bodily integrity could help in applying this general statement to concrete cases and could ultimately empower girls through measures that respect and guarantee their rights because this emphasis on capability shifts the focus to the girl herself.

The need to preserve the bodily integrity of girls could have a double function in policy-making. First, it could be used as a theoretical tool to detect unnoticed instances of injustice, and ascertain whether the best interests of girls are being respected in a given policy or law. Second, it could contribute, as a filter, to scrutinize the moral validity of political proposals, checking whether a given proposal would respect the three areas of a girls' bodily integrity in both the short-term and long-term, not only from a financial and physical standpoint, but also in relation to her psychological development and agency. The focus on agency, self-relation, and health that provides the capability of bodily integrity could help to place the girl in the resourceful role of a valid agent of change related to her daily experiences. This may well help to develop measures more in line with each girl's reality and needs. Although a discussion on how this could be implemented in concrete policies is beyond the scope of this article, adding an obligation to check, at an institutional level, whether a policy poses a threat to this capability and its aforementioned three main fields could function as an initial preventative step and improve social awareness concerning the challenges to girls of girlhood.

Introducing a right to bodily integrity for girls differs from positive discrimination measures that are designed to rebalance an asymmetric situation, favoring those who are under adverse conditions. Rather, introducing special checks and filters in the three areas that make up bodily integrity could help eradicate those adverse conditions by guaranteeing that deeply socially 
accepted and biased assumptions do not make it into public policies. Otherwise, those policies could turn into instances of injustice when applied to girls. Examples could include anything from initiation rituals in puberty to questionable procedures in beauty contests for girls. Similarly, one might think that such a direction in policy-making could conflict with parental rights since in many moral and political dilemmas the rights of two different subjects of rights may collide. However, here the conflict could be solved by increasing parental skills through preventative educational interventions. Likewise, this conflict would entail an asymmetry, which differs from cases when two adult subjects of rights find that one's right to autonomy could interfere with someone else's right to justice. In this case, parents or caregivers are subjects of rights with a specific obligation to help fulfill girls' rights, since they, alongside states and institutions, are the main agents of justice in relation to girls' well-being and well-becoming.

Finally, this could lead to tensions between a universal theory of justice and the respect for cultural variations. However, as previously mentioned, the dimensions of bodily integrity are simultaneously concrete and flexible enough to be applied in a context-sensitive way both in terms of a girl's maturity, and a girl's social and cultural setting without a given religion, tradition or culture overtaking her rights. This idea becomes clearer if human rights are connected to bodily integrity since abstract notions such as culture, tradition or religion would lack that dimension. Certainly, traditional rituals may result in huge violations of a girl's bodily integrity, whereas others may be neutral. Nevertheless, certain cultural habits might subtly harm girls' bodily integrity, such as street sexual harassment also known as catcalling, which is still a common practice and is frequently considered a way of complimenting girls for their physical appearance but is actually about (male) power. The capability/functioning of bodily integrity is therefore especially useful in these cases, first because even western societies tend to react to severe cases of violence and crime but hardly detect the daily soft violence that feeds sexism as an instance of injustice, and second, because the right to bodily integrity has the potential to make the connections between different rights explicit and visible.

Mar Cabezas is a postdoctoral researcher at the Centre for Ethics and Poverty Research at the University of Salzburg. Her main research interests centre on metaethics, moral philosophy, and human rights. 
GotTfried SChWEIGer works at the Centre for Ethics and Poverty Research at the University of Salzburg. His recent publications include $A$ Philosophical Examination of Social Justice and Child Poverty (2015) and Ethics and the Endangerment of Children's Bodies (2016).

\section{Acknowledgement}

The research for this article was funded by the Austrian Science Fund (FWF): P26480.

\section{Notes}

1. See http://www.ungei.org/

2. Both discourses have been accused of eurocentrism. These discourses, it is sometimes said, imply a new form of cultural imperialism as products of liberalism.

3. We are well aware of the devastating effects of abuse on boys and, without ignoring their experiences, we point out only how girls' knowing that they have more chances of being sexually assaulted just because of their sex affects their identity formation and decisions.

4. The concept of fertile capabilities should be interpreted, as suggested by Anver deShalit and Jonathan Wolf, in the sense of fruitful: "First there are those where a disadvantage in one functioning leads to disadvantages in others. This we have called a 'corrosive disadvantage'. In other cases, doing well in one functioning will lead to improvements in other functionings. This we have named a 'fertile functioning"' (2007:133-134).

5. Soft paternalism refers to acts carried out for the well-being but against the will of less than substantially autonomous agents (Schramme 2015).

\section{References}

Aggleton, Peter, and Richard Guy Parker, eds. 2012. Routledge Handbook of Sexuality, Health and Rights. London: Routledge.

Appell, Annette. 2009. "The Pre-Political Child of Child-Centered

Jurisprudence." Houston Law Review 46, no. 3: 703-757.

Bagattini, Alexander. 2014. "Child Well-Being: A Philosophical Perspective." Pp.

163-186 in The Handbook of Child Well-Being: Theory, Indicators, Measures

and Policies, ed. Asher Ben-Arieh, Ferran Casas, Ivar Frønes, and Jill E.

Korbin. New York: Springer. 
Bagattini, Alexander, and Colin M. Macleod, eds. 2014. The Nature of Children's Well-Being: Theory and Practice. New York: Springer.

Bunting, Annie. 2005. "Stages of Development: Marriage of Girls and Teens as an International Human Rights Issue." Social \& Legal Studies 14, no. 1: 1738. doi:10.1177/0964663905049524

Claassen, Rutger. 2014. "Capability Paternalism." Economics and Philosophy 30, no. 1: 57-73. doi:10.1017/S0266267114000042

Conroy, Kathleen, Megan Sandel, and Barry Zuckerman. 2010. "Poverty Grown Up: How Childhood Socioeconomic Status Impacts Adult Health." Journal of Developmental \& Behavioral Pediatrics 31, no. 2: 154-60. doi:10.1097/DBP.0b013e3181c21a1b

Cook, R, and B.M. Dickens. 2000. "Recognizing Adolescents' 'Evolving Capacities' to Exercise Choice in Reproductive Healthcare." International Journal of Gynecology \& Obstetrics 70, no. 1: 13-21. doi:10.1016/S00207292(00)00220-4

Cowie, Helen. 2012. From Birth to Sixteen Years: Children's Health, Social, Emotional, and Cognitive Development. New York: Routledge.

Croll, Elisabeth J. 2006. "From the Girl Child to Girls' Rights." Third World Quarterly 27, no. 7: 1285-1297. doi:10.1080/01436590600933669

DeGue, Sarah, Thomas R. Simon, Kathleen C. Basile, Sue Lin Yee, Karen Lang, and Howard Spivak. 2012. "Moving Forward by Looking Back: Reflecting on a Decade of CDC's Work in Sexual Violence Prevention, 2000-2010." Journal of Women's Health 21, no. 12: 1211-1218. doi:10.1089/jwh.2012.3973

Deneulin, Séverine, and J. Allister McGregor. 2010. "The Capability Approach and the Politics of a Social Conception of Wellbeing." European Journal of Social Theory 13, no. 4: 501-519. doi:10.1177/1368431010382762

Dixon, Rosalind, and Martha Nussbaum. 2012. "Children's Rights and a Capabilities Approach: The Question of Special Priority." Cornell Law Review 97: 549-593.

Eamon, Mary Keegan. 2002. "Poverty, Parenting, Peer, and Neighborhood Influences on Young Adolescent Antisocial Behavior." Journal of Social Service Research 28, no. 1: 1-23. doi:10.1300/J079v28n01_01

Faizi, A. A. A., and T. M. Shah. 2014. "Contract Farming and Gender Relations in India." Journal of Land and Rural Studies 2, no. 2: 191-214. doi: $10.1177 / 2321024914534041$

Felix, Erika D., and Susan D. MacMahon. 2006. "Gender and Multiple Forms of Peer Victimization: How Do They Influence Adolescent Psychosocial Adjustment?" Violence and Victims 21, no. 6: 707-724.

Finkelhor, David. 1993. "Epidemiological Factors in the Clinical Identification of Child Sexual Abuse." Child Abuse \& Neglect 17, no. 1: 67-70. doi:10.1016/0145-2134(93)90009-T 
Garbarino, James. 2000. Lost Boys: Why Our Sons Turn Violent and How We Can Save Them. New York: Anchor Books.

Gilligan, Carol. 1993. In a Different Voice: Psychological Theory and Women's Development. Cambridge, Mass: Harvard University Press.

Greene, Sheila. 2015. The Psychological Development of Girls and Women: Rethinking Change in Time. Women and Psychology. East Sussex: Routledge. Hayes, Sharon, and Stacey Tantleff-Dunn. 2010. "Am I Too Fat to Be a Princess? Examining the Effects of Popular Children's Media on Young Girls' Body Image." British Journal of Developmental Psychology 28, no. 2: 413-426. doi:10.1348/026151009X424240

Held, Virginia, ed. 1995. Justice and Care: Essential Readings in Feminist Ethics. Boulder, Colo: Westview Press.

Honneth, Axel. 2004. "Recognition and Justice: Outline of a Plural Theory of Justice.” Acta Sociologica 47, no. 4: 351-364.

doi:10.1177/0001699304048668

Horgan, Goretti. 2009. “'That Child Is Smart Because He's Rich': The Impact of Poverty on Young Children's Experiences of School.” International Journal of Inclusive Education 13, no. 4: 359-376. doi:10.1080/13603110802707779

Ignatieff, Michael. 2001. Human Rights as Politics and Idolatry. University Center for Human Values Series. Princeton, N.J: Princeton University Press.

Landry, Susan H., and Cary L. Cooper, ed. 2014. Wellbeing in Children and Families. Wellbeing: A Complete Reference Guide, Volume I. Chichester, West Sussex: John Wiley \& Sons.

LeMaire, Kelly L., Debra L. Oswald, and Brenda L. Russell. 2016. "Labeling Sexual Victimization Experiences: The Role of Sexism, Rape Myth Acceptance, and Tolerance for Sexual Harassment." Violence and Victims 31, no. 2: 332-346. doi:10.1891/0886-6708.VV-D-13-00148

McKenney, S. J., and R. S. Bigler. 2016. "Internalized Sexualization and its Relation to Sexualized Appearance, Body Surveillance, and Body Shame Among Early Adolescent Girls." The Journal of Early Adolescence 36, no. 2: 171-197. doi:10.1177/0272431614556889

Melrose, Margaret, and Jenny Pearce, eds. 2013. Critical Perspectives on Child Sexual Exploitation and Related Trafficking. Basingstoke: Palgrave Macmillan. Mendus, Susan. 2000. Feminism and Emotion: Readings in Moral and Political Philosophy. Basingstoke, Hampshire: Macmillan; New York: St. Martin's Press. Nussbaum, Martha. 2000. Women and Human Development-The Capabilities Approach. Cambridge/New York: Cambridge University Press.

Nussbaum, Martha. 2003. "Capabilities as Fundamental Entitlements: Sen and Social Justice." Feminist Economics 9, no. 2/3: 33-59. doi: $10.1080 / 1354570022000077926$ 
Nussbaum, Martha. 2005. "Women's Bodies: Violence, Security, Capabilities." Journal of Human Development 6, no. 2: 167-183. doi:10.1080/14649880500120509

Nussbaum, Martha. 2011. Creating Capabilities: The Human Development Approach. Cambridge, MA and London: Belknap Press of Harvard University Press.

Pinheiro, Paulo Sérgio. 2006. World Report on Violence against Children. Geneva: United Nations Publ.

Pitillas, Carlos, and Blanca Gómez. 2014. "La Situación de La Infancia En 'El Gallinero.' Los Derechos Humanos También Son Cosa de Niños.” [The situation of children in the "Gallinero." Human rights are also kids' stuff]. Save the Children/Universidad de Comillas: Madrid.

Plumwood, Val. 1993. Feminism and the Mastery of Nature. London and New York: Routledge. http://site.ebrary.com/id/10058322

Rafferty, Yvonne. 2013. "International Dimensions of Discrimination and Violence against Girls: A Human Rights Perspective." Journal of International Women's Studies 14, no. 1: 1-23.

Robeyns, Ingrid. 2003. "Sen's Capability Approach and Gender Inequality: Selecting Relevant Capabilities." Feminist Economics 9, no. 2/3: 61-92. doi:10.1080/1354570022000078024

Sauer, Pieter J. J., and David Neubauer. 2014. "Female Genital Mutilation: A Hidden Epidemic (Statement from the European Academy of Paediatrics)." European Journal of Pediatrics 173, no. 2: 237-238. doi:10.1007/s00431-0132126-0

Schramme, Thomas, ed. 2015. New Perspectives on Paternalism and Health Care. New York: Springer.

Sen, Amartya. 1993. "Capability and Well-Being." Pp. 30-53 in The Quality of Life, ed. Martha Nussbaum and Amartya Sen. Oxford: Clarendon Press.

Sen, Amartya. 1997. "Rights and Capabilities." Pp. 307-324 in Resources, Values, and Development: Expanded Edition, ed. Amartya Sen. Cambridge, MA: Harvard University Press.

Sen, Amartya. 2005. "Human Rights and Capabilities." Journal of Human Development 6, no. 2: 151-166. doi:10.1080/14649880500120491

Shute, Rosalyn, Larry Owens, and Phillip Slee. 2008. "Everyday Victimization of Adolescent Girls by Boys: Sexual Harassment, Bullying or Aggression?” Sex Roles 58, no. 7-8: 477-489. doi:10.1007/s11199-007-9363-5

Taefi, Nura. 2009. "The Synthesis of Age and Gender: Intersectionality, International Human Rights Law and the Marginalisation of the Girl-Child." The International Journal of Children's Rights 17, no. 3: 345-376. doi:10.1163/157181809X458049 
Tong, Rosemarie, Anne Donchin, and Susan Dodds, ed. 2004. Linking Visions: Feminist Bioethics, Human Rights, and the Developing World. Lanham, MD: Rowman \& Littlefield Publishers.

United Nations General Assembly, Convention on the Rights of the Child, 20 November 1989, United Nations, Treaty Series, vol. 1577, P. 3. http://www.ohchr.org/Documents/ ProfessionalInterest/crc.pdf (accessed 4 July 2016).

United Nations General Assembly, 1995. Report of the Fourth World Conference on Women. http://www.un.org/womenwatch/daw/beijing/pdf/Beijing\%20full \%20report\%20E.pdf. (accessed 4 July 2016).

Unterhalter, Elaine, Rosie Vaughan, and Melanie Walker. 2007. "The Capability Approach and Education.” Prospero 13, no. 3: 13-21.

Upmark, Marianne, Karin Borg, and Kristina Alexanderson. 2007. "Gender Differences in Experiencing Negative Encounters with Healthcare: A Study of Long-Term Sickness Absentees." Scandinavian Journal of Public Health 35, no. 6: 577-584. doi:10.1080/14034940701362194

Warren, Karen. 1990. "The Power and the Promise of Ecological Feminism." Environmental Ethics 12, no. 2: 125-146.

Wolff, Jonathan, and Avner de-Shalit. 2007. Disadvantage. Oxford/New York: Oxford University Press.

Worell, Judith, and Carol D. Goodheart, eds. 2006. Handbook of Girls' and Women's Psychological Health. Oxford Series in Clinical Psychology. New York: Oxford University Press. 